\title{
Usefulness of Regional Bone Measurements in Patients With Osteoporotic Fractures of the Spine and Distal Forearm
}

\author{
Lisbeth Nilas, Jan Pødenphant, Bente Juel Riis, Anders Gotfredsen, \\ and Claus Christiansen
}

Department of Clinical Chemistry, University of Copenhagen, Glostrup Hospital, Denmark

\begin{abstract}
Bone mineral mass was measured in normal subjects and osteoporotic patients at two forearm sites (proximal and distal of the $8 \mathrm{~mm}$ site between the two forearm bones) by single photon absorptiometry and in the spine and whole body by dual photon absorptiometry. There were no signs of preferential low spinal bone mass in 28 patients with vertebral fractures. Their bone mass was at all sites $26 \%$ to $37 \%$ lower than the premenopausal mean value and $7 \%$ to $13 \%$ lower than in age-matched normal women. In 45 patients with forearm fractures bone reduction was also universal but only $3 \%$ to $6 \%$ lower than in healthy women of comparable age. The spinal bone mass in all the patients was significantly related to both forearm measurements with coefficients of correlation of $0.58-0.61$ and s.e.e. of $18 \%$. Compared to the premenopausal normal range the distal forearm site had a greater sensitivity in identifying patients with vertebral fractures than had the spinal measurement (chi-square test, $p<0.01$ ). We thus conclude that patients with vertebral fractures have universal osteoporosis and that measurement of spinal BMC had no predictive advantages over that of the forearm bone mass for population studies.
\end{abstract}

J Nucl Med 28:960-965, 1987

B one mass in young, healthy women in different regions is interrelated while the representativity of local bone measurements has been questioned in elderly and osteoporotic women $(1,2)$. Although studies indicate that the rate of trabecular bone loss exceeds the cortical loss in the first postmenopausal years $(3,4)$, bone is lost from all parts of the skeleton (5). In elderly women, the reduction in bone mass is the same at central and peripheral measuring sites (6) and in osteoporotic patients with hip fracture it is uniformly low (6-8). Many factors influence the rate of bone loss. Some individuals will lose more than others at individual sites, and fractures are likely to occur at sites with the lowest bone mass.

The prevalence of fractures of the distal forearm and the spine increases rapidly a few years after the menopause. It has been claimed that vertebral fractures are the result of a predominant loss of trabecular bone (8), and a preferential low spinal bone mass, estimated by

Received Mar. 24, 1986; revision accepted Dec. 23, 1986.

For reprints contact: Lisbeth Nilas, Dept. of Clinical Chemistry, University of Copenhagen, Glostrup Hospital, DK-2600 Glostrup, Denmark. the dual photon technique, has been found in these patients $(9,10)$.

We have recently developed a method for measuring bone mass in the very distal forearm and have shown that on a group basis this is a valid estimate of spinal bone mass in premenopausal and early postmenopausal women (3) and in patients with hip fractures (6). The question therefore arises whether the very distal forearm can substitute the more expensive spinal measurement in estimating bone mass in women with vertebral fractures. Examination of this question was the aim of the present study.

\section{PATIENTS AND METHODS}

The study comprised 73 osteoporotic patients, 28 with vertebral fracture and $\mathbf{4 5}$ with forearm fracture. The patients with vertebral fracture were found by reassessing all spinal $x$ rays taken of women aged 55 to $75 \mathrm{yr}$ during the last $5 \mathrm{yr}$ at our institution. The 28 patients were a representative sample of women found to have at least one osteoporotic fracture (wedge or compression). The patients with forearm fracture were a random sample of all women referred to the hospital because of Colles' fracture in the same period. In all patients 
the fracture had occurred more than 6 mo previously and none had other diseases known to affect calcium metabolism. All gave their informed consent to participate in the study. A control group of 17 healthy postmenopausal women was included, and further comparison was made with 45 healthy premenopausal women. The healthy women were mainly members of the hospital staff, their relatives and members of a local pensioners social club.

Local forearm bone mass (BMC) was measured by single photon absorptiometry in the ulna and radius of both forearms (3). Proximal BMC is the mean of six scans $4 \mathrm{~mm}$ apart proximal of the $8 \mathrm{~mm}$ site and distal BMC is the mean of four scans $2 \mathrm{~mm}$ apart distal of the starting point. Fat correction was performed in each scan line by constructing a new baseline $B_{1}$ from the formula: $B_{1}=\left(B_{2}-B_{0}\right) \times 0.4 \pm B_{0}$ where $B_{0}$ is the baseline obtained in water and $B_{2}$ is the maximal deviation at the two sides of the bones owing to subcutaneous fat. With normal physiological variations in the fat content, the method corrects accurately $(y=0.99 x+1.2)$. In each scan line the "density" (BMD) is calculated as BMC divided by the sum of the widths of the ulna and radius. Proximal and distal BMD are the mean values of the six proximal and four distal scans, respectively.

Spinal bone mass and density were measured by dual photon technique ${ }^{\dagger}(11)$, by obtaining 40 scan lines $4.5 \mathrm{~mm}$ apart over the lumbar vertebrae with an $8 \mathrm{~mm}$ collimator. The individual vertebrae were identified on the display and bone edges and base lines were adjusted. Spinal BMC was calculated in the vertebrae $L_{2}, L_{3}$, and $L_{4}$ including the intervertebral disks. Spinal BMD was calculated as spinal BMC divided by the projected scan area.

Total-body bone mass (TBBM) was measured by dual photon absorptiometry using a 1-Ci gadolinium- 153 source (12). The patient lay supine and was scanned in a rectilinear pattern with longitudinal steps of $2.5 \mathrm{~cm}$. Data were collected in 0.5 -sec intervals yielding $\sim 2,000$ pixels containing bone and 3,000 pixels soft tissue. In all pixels containing bone the bone mass was calculated and calibrated into gram mineral using defatted bone standards. The long-term precision of the measurements were $1.2 \%$ (proximal BMC), $1.6 \%$ (distal BMC), 5.5\% (spinal BMC), 6.2\% (spinal BMD) and $2.1 \%$ (TBBM). The coefficient of correlation between measured and actual bone mass was between 0.94 and 0.99 for all measurements (6).

The serum and urine concentrations of calcium, phosphate, alkaline phosphatases, and creatinine were measured by routine techniques, and hydroxyproline (HPR) by spectrophotometry (13). The calcium and HPR concentrations in urine samples collected after an overnight fast were corrected for creatinine excretion.

\section{CALCULATIONS}

Forearm BMC and BMD in the normal subjects were expressed as the mean of the values in the two forearms. In those with a history of Colles' fracture only the readings of the nonfractured arm were used. When fracture had occurred in both forearms (four patients) the mean of the two readings was used. The number of fractures in the right and left forearm was evenly distributed.

Biochemical results and bone measurements in subgroups were compared by Student's t-test for unpaired data. The individual bone measurements in the fracture patients were expressed in $\mathrm{z}$ scores (difference between measurements expressed in standard deviations) compared with both the premenopausal and the postmenopausal control groups. In each patient group the reduction in bone mass at the different sites was tested by one way analysis of variance. For the two fracture groups the sensitivity of the regional bone measurements was calculated as the fraction of patients with bone mass values below premenopausal normal range, i.e., the number of true positive/true positive + false negative. The difference in the number of patients falling under this level was tested by a chisquare test. Linear regression analysis was used to test relationships between different bone measurements and was expressed as the coefficient of regression $(r)$ and the s.e.e.

\section{RESULTS}

The women in the two fracture groups were hypocalcemic, compared with the age-matched healthy women, and the conventional biochemical measurements indicated a high bone turnover in the women with spinal fracture (Table 1).

There was a large overlap between the bone measurements in the fracture patients and those in the healthy older women (Table 2). The reduction ranged from $7 \%$

TABLE 1

Age, Height, and Calcium Metabolic Variables in Healthy Women and Women with Fractures

\begin{tabular}{|c|c|c|c|c|}
\hline & \multicolumn{2}{|c|}{ Healthy women } & \multicolumn{2}{|c|}{ Women with fractures } \\
\hline & $\begin{array}{l}\text { Premenopausal } \\
\quad(n=45)\end{array}$ & $\begin{array}{l}\text { Postmenopausal } \\
(n=17)\end{array}$ & $\begin{array}{l}\text { Forearm } \\
(n=45)\end{array}$ & $\begin{array}{c}\text { Spine } \\
(n=28)\end{array}$ \\
\hline $\begin{array}{l}\text { Age }(\mathrm{yr}) \\
\text { Height (cm) } \\
\text { Serum Ca }(\mathrm{mmol} / \mathrm{l}) \\
\text { Serum P (mmol/) } \\
\text { Serum AP (U/l) } \\
\text { FU Ca/Cr }(\mathrm{mmol} / \mathrm{mol}) \\
\text { FU HPR/Cr }(\mathrm{mmol} / \mathrm{mol})\end{array}$ & $\begin{aligned} 40.0 & \pm 6.6^{\ddagger} \\
164.7 & \pm 6.9^{\circ} \\
2.46 & \pm 0.08^{\circ} \\
1.13 & \pm 0.18 \\
134 & \pm 45^{\circ} \\
189 & \pm 127^{\dagger} \\
9.7 & \pm 3.1^{\circ}\end{aligned}$ & $\begin{aligned} 66.2 & \pm 6.2 \\
160.4 & \pm 6.0 \\
2.51 & \pm 0.08 \\
1.13 & \pm 0.12 \\
171 & \pm 57 \\
291 & \pm 139 \\
12.3 & \pm 4.1\end{aligned}$ & $\begin{aligned} 64.8 & \pm 5.5 \\
160.1 & \pm 5.9 \\
2.40 & \pm 0.12^{\ddagger} \\
1.18 & \pm 0.15 \\
179 & \pm 52 \\
347 & \pm 234 \\
14.8 & \pm 5.5\end{aligned}$ & $\begin{array}{l}68.3 \pm 4.6 \\
59.5 \pm 6.5 \\
2.40 \pm 0.07^{\ddagger} \\
1.32 \pm 0.13^{\ddagger} \\
216 \pm 74^{\circ} \\
470 \pm 257^{\dagger} \\
14.4 \pm 5.2\end{array}$ \\
\hline
\end{tabular}


TABLE 2

Regional Bone Mass and Density in Healthy Women and Women with Fractures

\begin{tabular}{|c|c|c|c|c|}
\hline & \multicolumn{2}{|c|}{ Healthy women } & \multicolumn{2}{|c|}{ Women with fractures } \\
\hline & $\begin{array}{l}\text { Premenopausal } \\
\qquad(n=45)\end{array}$ & $\begin{array}{l}\text { Postmenopausal } \\
(n=17)\end{array}$ & $\begin{array}{l}\text { Forearm } \\
(n=45)\end{array}$ & $\begin{array}{c}\text { Spine } \\
(n=28)\end{array}$ \\
\hline $\begin{array}{l}\text { Proximal BMC }(u) \\
\text { Proximal BMD }(u / \mathrm{mm}) \\
\text { Distal BMC }(u) \\
\text { Distal BMD }(u / \mathrm{mm}) \\
\text { Spinal BMC }(\mathrm{g}) \\
\text { Spinal BMD }\left(\mathrm{g} / \mathrm{cm}^{2}\right) \\
\text { TBBM }\end{array}$ & $\begin{array}{l}41.3 \pm 4.5^{\ddagger} \\
1.47 \pm 0.15^{\ddagger} \\
41.6 \pm 4.9^{\ddagger} \\
1.11 \pm 0.14^{\ddagger} \\
46.9 \pm 7.5^{\ddagger} \\
1.03 \pm 0.13^{\ddagger} \\
3,426 \pm 495^{\ddagger}\end{array}$ & $\begin{array}{l}31.6 \pm 5.1 \\
1.05 \pm 0.16 \\
30.0 \pm 6.2 \\
0.77 \pm 0.17 \\
36.8 \pm 6.1 \\
0.82 \pm 0.14 \\
2,593 \pm 471\end{array}$ & $\begin{array}{l}29.5 \pm 5.7 \\
1.01 \pm 0.16 \\
29.2 \pm 6.0 \\
0.75 \pm 0.14 \\
35.6 \pm 7.7 \\
0.78 \pm 0.14 \\
2.434 \pm 420\end{array}$ & $\begin{array}{l}28.8 \pm 5.6 \\
0.93 \pm 0.22 \\
26.1 \pm 5.0^{\circ} \\
0.68 \pm 0.16 \\
34.2 \pm 7.6 \\
0.76 \pm 0.13 \\
2,359 \pm 479\end{array}$ \\
\hline
\end{tabular}

to $13 \%$ in the spinal fracture group and from $3 \%$ to $6 \%$ in the forearm fracture group. Regional and total bone mass were reduced in a similar pattern in the three groups of older women, compared with the premenopausal women (Fig. 1). The reduction ranged from $24 \%$ to $32 \%$ in the forearm fracture group, $26 \%$ to $37 \%$ in the spinal fracture group, and $20-29 \%$ in the healthy postmenopausal group. Apart from bone density values

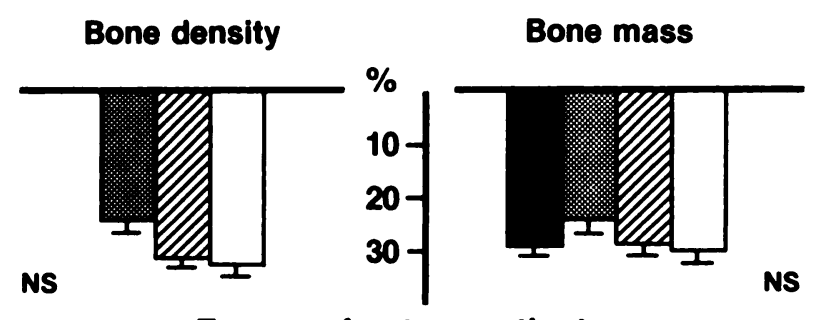

Forearm fracture patients

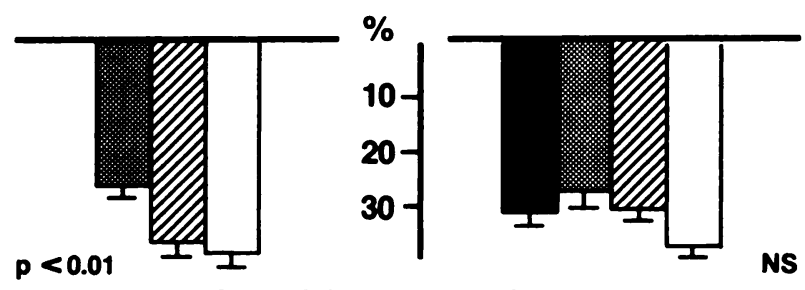

Spinal fracture patients

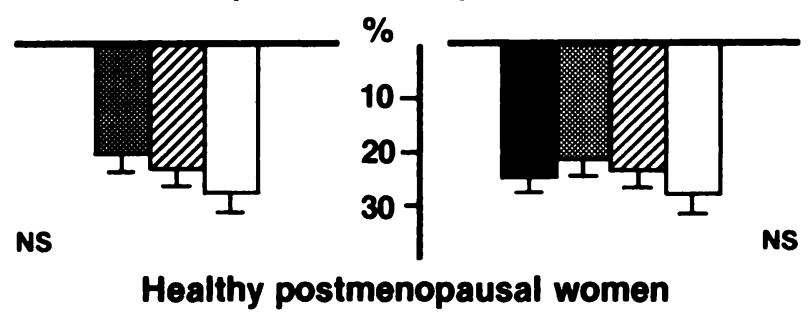

FIGURE 1

Regional and total bone mass in patients with fracture and healthy age-matched women in percent of the mean value in premenopausal women. Values given as mean -1 s.e.m. Differences of means are tested by one-way analysis of variance. (口) TBBM; (r) Proximal BMC/BMD; (口) Spinal BMC/BMD; (口) Distal BMC/BMD. in the spinal fracture group, analysis of variance showed identical reduction at all sites in both patients and normal subjects.

The 28 patients with spinal osteoporosis had a total of 136 vertebral fractures (mean 4.9; median 3 ) of which 32 were in the lumbar region. Forty-five percent of the fractures were end-plate deformities only, $40 \%$ anterior wedge deformities and $15 \%$ compression fractures. The three types of fractures were given a score of 1,2 , or 3 (14). The individual scores ranged from 3 to 25 (mean 8.3, median 6). Ten of the patients had collapsed vertebrae (mean score 13), and, compared with the remaining 18 patients with vertebral osteoporosis (mean score 7), their BMC values were 4.1-5.6\% lower at the two forearm sites and $2.3 \%$ lower in the spine.

In patients with vertebral fractures the coefficient of correlation between either of the forearm measurements and spinal BMC was modest, but significant (proximal BMC: $r=0.58$, distal BMC: $r=0.61$ ) with standard errors of $18 \%$. The relationships were not increased by including the wrist fracture patients.

When the differences in the bone measurements of the fracture patients and healthy age-matched women were expressed in $\mathrm{z}$ scores, the reduction in bone mass was uniform in both fracture groups (one-way analysis of variance, $p>0.05$ ) (Table 3). Compared with premenopausal women a nonuniform reduction in bone values was found in both the fracture groups $(p<0.001)$ and the health older women $(p<0.05)$ with the largest reduction in the peripheral skeleton. At most sites bone density was reduced more than bone mass. Table 3 and Fig. 2 show the ratio of the fracture patients with bone values below those of the premenopausal normal range (mean -2 s.d.). Of the 28 patients with vertebral fracture 25 had values below the premenopausal level at the distal forearm site and 12 of the 28 had spinal bone mass below this level. This difference is significant, chisquare test, $p<0.001$. For the distal forearm and spinal density the corresponding numbers were 24 and 15 (p $<0.01$ ). The distal and proximal forearm sites distinguished equally. 
TABLE 3

z Scores of Bone Measurements Calculated from Pre- and Postmenopausal Normal Ranges.

\begin{tabular}{|c|c|c|c|c|c|c|c|c|c|c|}
\hline & & \multicolumn{4}{|c|}{ Bone density } & \multicolumn{5}{|c|}{ Bone mass } \\
\hline & & Spine & Prox & Dist & $\mathbf{P}$ & TBBM & Spine & Prox & Dist & $\mathbf{P}$ \\
\hline $\begin{array}{l}\text { z Score from } \\
\text { postmenopausal } \\
\text { normal range }\end{array}$ & $\begin{array}{l}\text { Forearm fracture } \\
\text { Spinal fracture }\end{array}$ & $\begin{array}{c}-0.25 \\
(1.02) \\
-0.43 \\
(0.95)\end{array}$ & $\begin{array}{c}-0.28 \\
(1.02) \\
-0.49 \\
(1.20)\end{array}$ & $\begin{array}{c}-0.15 \\
(0.83) \\
-0.51 \\
(0.92)\end{array}$ & $\begin{array}{l}\text { N.S. } \\
\text { N.S. }\end{array}$ & $\begin{array}{c}-0.34 \\
(0.89) \\
-0.50 \\
(1.00)\end{array}$ & $\begin{array}{c}-0.20 \\
(1.26) \\
-0.42 \\
(1.25)\end{array}$ & $\begin{array}{c}-0.41 \\
(1.12) \\
-0.54 \\
(1.12)\end{array}$ & $\begin{array}{c}-0.13 \\
(0.97) \\
-0.51 \\
(0.92)\end{array}$ & $\begin{array}{l}\text { N.S. } \\
\text { N.S. }\end{array}$ \\
\hline $\begin{array}{l}\text { z Score from } \\
\text { premenopausal } \\
\text { normal range }\end{array}$ & $\begin{array}{l}\text { Healthy postmenopausal } \\
\text { Forearm fracture } \\
\text { Spinal fracture }\end{array}$ & $\begin{array}{c}-1.68 \\
(1.13) \\
-1.82 \\
(1.09) \\
-2.00 \\
(1.01)\end{array}$ & $\begin{array}{c}-2.76 \\
(1.03) \\
-3.04 \\
(1.05) \\
-3.26 \\
(1.24)\end{array}$ & $\begin{array}{c}-2.38 \\
(1.18) \\
-2.55 \\
(0.97) \\
-2.98 \\
(1.08)\end{array}$ & $\begin{array}{l}<0.05 \\
<0.001 \\
<0.001\end{array}$ & $\begin{array}{c}-1.68 \\
(0.92) \\
-2.01 \\
(0.85) \\
-2.16 \\
(0.95)\end{array}$ & $\begin{array}{c}-1.35 \\
(0.81) \\
-1.49 \\
(1.03) \\
-1.69 \\
(1.01)\end{array}$ & $\begin{array}{c}-2.16 \\
(1.33) \\
-2.62 \\
(1.26) \\
-2.77 \\
(1.25)\end{array}$ & $\begin{array}{c}-2.37 \\
(1.26) \\
-2.53 \\
(1.23) \\
-3.12 \\
(1.08)\end{array}$ & $\begin{array}{l}<0.05 \\
<0.001 \\
<0.001\end{array}$ \\
\hline Sensitivity & $\begin{array}{l}\text { Forearm fracture } \\
\text { Spinal fracture }\end{array}$ & $\begin{array}{l}0.55 \\
0.54\end{array}$ & $\begin{array}{l}0.84 \\
0.89\end{array}$ & $\begin{array}{l}0.62 \\
0.86\end{array}$ & & $\begin{array}{l}0.64 \\
0.36\end{array}$ & $\begin{array}{l}0.40 \\
0.43\end{array}$ & $\begin{array}{l}0.73 \\
0.86\end{array}$ & $\begin{array}{l}0.84 \\
0.89\end{array}$ & \\
\hline
\end{tabular}

- The diagnostic sensitivity is given, using the premenopausal normal range.

Values are given as mean and (s.d.) P = probability of identical means (one-way analysis of variance).

\section{DISCUSSION}

There are three different, often used, definitions of osteoporosis. One is that it is the condition when osteo- porotic fractures occur. A second, that it is a condition where bone mass is lower than that predicted from an age matched normal range (15), but as $30 \%$ of women $70-80$ yr old have had an osteoporotic fracture $(16,17)$
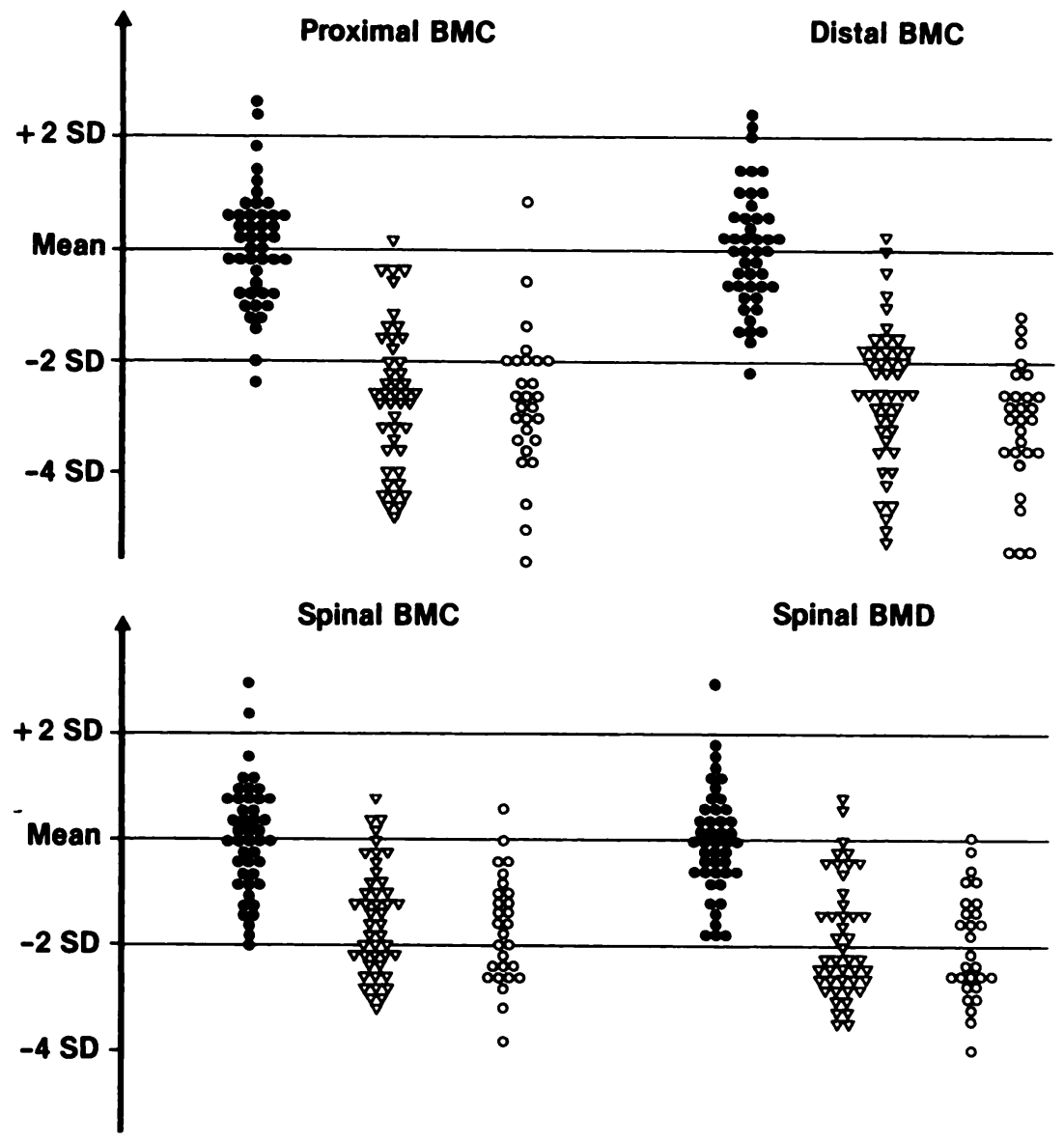

FIGURE 2

Individual values of forearm and spinal bone mass in patients with fracture of the forearm $(\Delta)$ and spine (open circles), given on a scale defined from the mean and s.d. in healthy premenopausal women (O). 
and the frequency of other diseases increases with age, an age matched normal group would have to be highly selective. And third, osteoporosis is defined as a condition where bone mass is below a certain level, the fracture threshold (17). As osteoporotic fractures are extremely uncommon in premenopausal women, and only a slight reduction of their bone mass increases the risk of fractures, we find it reasonable to compare the bone mass of patients with the lower limit of the premenopausal normal range.

In recent years we have measured bone mass in 94 normal premenopausal women with a mean age of 41.0 $\pm 3.1 \mathrm{yr}$. The proximal BMC in the $\mathbf{4 5}$ women in this study constitutes $100.7 \%$ of the mean value in the larger group, and the standard deviations were similar in the two populations. Furthermore, we have recently published data from 161 early postmenopausal women (mean age $50.1 \mathrm{yr}$ ) and in this population the mean proximal BMC was $39.8 \pm 5.4$ units (18). The proximal BMC in the postmenopausal group was $96 \%$ of a 5 year grouped age-matched normal population of women. The present samples of pre- and postmenopausal women are thus representative.

The two patient groups consisted of unselected patients with fracture consecutively referred to our institution 1-5 yr previously. Furthermore, Krølner et al. (19) have found that the forearm bone mass of patients with Colles' fracture is $295 \%$ of age-matched women, which is similar to our findings.

To avoid unconscious bias the study was done blindly, with the patients in the two groups visiting the department in random order. Both forearms were scanned in all cases. The measurement of spinal bone mass requires manual definition of bone edges and baselines. We therefore displayed and recalculated nine of the spinal measurements in the group with vertebral fractures and ten in a group of premenopausal women. The inter technician errors were: spinal BMC 6.1\% and $1.1 \%$, respectively, spinal BMD $3.1 \%$ and $0.9 \%$, respectively. This indicates that in the clinical setting spinal bone mass can be measured at a precise level in patients without fractures, whereas the error increases dramatically if the patient has a fracture. Calculation of forearm BMC is not subject to technician error, because the software defines bone edges and baselines.

This study shows that patients with vertebral and forearm fractures have a universal low mass, and that there are no signs of preferential spinal bone loss either compared to premenopausal or to healthy postmenopausal women. A universal low bone mass has also been found in patients with hip fracture (6). These results agree with the finding that the occurrence of various types of osteoporotic fractures coincide $(16,17)$. As in other studies we find a large overlap between the bone mass of normal subjects and that of patients with osteoporotic fractures. Although the risk of fracture also depends on other factors $(20,21)$, there is a clear relation between the incidence of fractures and declining bone mass.

Unlike Mazess (1), who used a radial site dominated by cortical bone, we found a significant relationship between forearm and spinal bone mass in patients with vertebral fractures. The s.e.e. values of $18 \%$ suggest on the other hand that spinal BMC cannot be predicted from peripheral measurements or vice versa in single persons. It is possible that some of the differences between our results and those of others can be explained by different procedures in selecting the osteoporotic patients. Since trabecular bone loss seems to exceed cortical in the first years of the menopause, a preferential spinal bone loss may be found in patients who develop vertebral fractures at this time of life.

When bone mass is divided by bone width the individual variation is reduced in normal subjects $(18)$, and the density of peripheral bones seems slightly superior to bone mass in identifying patients with spinal osteoporosis. A greater reduction of bone mass at distal forearm sites than at proximal sites in patients with vertebral fractures has earlier been described $(22,23)$. Studies have also indicated that bone mass measurements in the very distal forearms have diagnostic advantages $(22,24)$, but in the present study there is no great difference in the predictive value of the two sites of spinal bone mass. Our data clearly show that measurements of bone mass in the forearms have a higher sensitivity for identifying groups of patients with vertebral fractures than has spinal bone mass. In this setting spinal measurements may thus have no predictive advantages in identifying patients at risk of such fractures.

\section{NOTES}

\footnotetext{
- Bone Mineral Analyzer 1100, Nuclear Data Corporation, Schaumburg, IL.

'DPS Scanner, Lunar Radiation Corporation, Madison, WI.
}

\section{REFERENCES}

1. Mazess RB, Peppler WW, Chesney RW, et al. Does bone measurement on the radius indicate skeletal status: concise communication. J Nucl Med 1984; 25:281-288.

2. Krølner B, Pors Nielsen S, Lund B, et al. Measurement of bone mineral content (BMC) of the lumbar spine, II. Correlation between forearm BMC and lumbar spine BMC. Scand J Clin Lab Invest 1980; 40:665670.

3. Nilas L, Borg J, Gotfredsen A, et al. Comparison of single- and dual-photon absorptiometry in postmenopausal bone mineral loss. J Nucl Med 1985; 26:12571262.

4. Smith DM, Norton JA, Khairi R, et al. The measurement of rates of mineral loss with aging. $J$ Lab Clin Med 1976; 87:882-892.

5. Gotfredsen A, Nilas L, Riis BJ, et al. Spontaneous and oestrogen caused bone changes in early postmenopau- 
sal women: a local or generalized phenomenon. $\mathrm{Br}$ Med J 1986; 292:1098-1100.

6. Nilas L, Gotfredsen A, Riis BJ, et al. The diagnostic validity of local and total bone mineral measurements in postmenopausal osteoporosis and osteoarthritis. Clin Endocrinol: in press.

7. Krølner B, Pors Nielsen S. Bone mineral content of the lumbar spine in normal and osteoporotic women: cross-sectional and longitudinal studies. Clin Sci 1982; 62:329-336.

8. Riggs BL, Wahner HW, Seeman E, et al. Changes in bone mineral density of the proximal femur and spine with aging. $J$ Clin Invest 1982; 70:716-723.

9. Riggs BL, Wahner HW, Dunn WL, et al. Differential changes in bone mineral density of the appendicular and axial skeleton with aging. $J$ Clin Invest 1981; 67:328-335.

10. Mazess RB, Peppler WW, Chesney RW. Total body and regional bone mineral by dual-photon absorptiometry in metabolic bone disease. Calcif Tissue Int 1984; 36:8-13.

11. Duun WL, Wahner HW, Riggs BL. Measurement of bone mineral content in human vertebrae and hip by dual photon absorptiometry. Radiology 1980; 136:485-487.

12. Gotfredsen A, Borg J, Christiansen C, et al. Total body bone mineral in vivo by dual photon absorptiometry. I. Measurement procedures. Clin Physiol 1984; 4:343355.

13. Pødenphant J, Larsen N-E, Christiansen C. An easy and reliable method for determination of urinary hydroxyproline. Clin Chim Acta 1984; 142:145-148.

14. Kleerekoper M, Parfitt AM, Ellis BI. Measurement of vertebral fracture rates in osteoporosis. In: Christiansen C, et al., eds. Osteoporosis. Aalborg: Stiftsbogtrykkeri, 1984: 103-106.
15. Stevenson JC, Whitehead MI. Postmenopausal osteoporosis. $\mathrm{Br}$ Med J 1982; 285:585-588.

16. Jensen GF, Christiansen C, Boesen J, et al. Epidemiology of postmenopausal spinal and long bone fractures. Clin Othop Rel Res 1982; 166:75-81.

17. Nordin BEC, Heyburn PJ, Peacock M, et al. Osteoporosis and osteomalacia. Clin Endocrinol Metab 1980; 9:177-205.

18. Nilas L, Gotfredsen A, Christiansen C. Total and local bone mass before and after normalization for indices of bone and body size. Scan J Clin Lab Invest 1986; 46:53-57.

19. Krølner B, Tøndevold E, Toft B, et al. Bone mass of the axial and the appendicular skeleton in women with Colles' fracture: its relation to physical activity. Clin Physiol 1982; 2:147-157.

20. Seeman E, Melton LJ, O'Fallon WM, et al. Risk factors for spinal osteoporosis in men. Am J Med 1983; 75:977-983.

21. Bastow MD, Rawlings J, Allison SP. Undernutrition hypothermia, and injury in elderly women with fractured femur: an injury response to altered metabolism. Lancet 1983; i:143-145.

22. Grubb SA, Jacobsen PC, Awbrey BJ, et al. Bone density in osteopenic women: a modified distal radius density measurement procedure to develop an "at risk" value for use in screening women. J Orthop Res 1984; 2:322-327.

23. Smith DM, Johnston CC, Yu P-L. In vivo measurement of bone mass. Its use in demineralized states such as osteoporosis. JAMA 1972; 219:325-329.

24. Hesp $R$, Deacon AC, Hulme $P$, et al. Trends in trabecular and cortical bone in the radius compared with whole body calcium balance in osteoporosis. Clin Sci 1984; 66:109-112. 